\title{
Synthesis, Characterization and Bioactivity of two Rare-Earth Complexes with Schiff base from Lysine- Salicylaldehyde
}

\author{
LI Yan \\ School of Nuclear Technology and Chemistry \& Biology, \\ Hubei University of Science and Technology, \\ Xiangning, 437100,China \\ Liyan750607@163.com
}

\begin{abstract}
Two novel rare earth complexes with Schiff base from Lysine-Salicylaldehyde were synthesized by using the drop by drop reaction. On the basis of molar conductance and elemental analysis, a formula of the target complex was given. Moreover, the target complexes were also characterized by IR and UVvisible. The antibacterial experiments indicated that the target complexes have good antibacterial activities against $S$. aureus, $E$. coli, B. subtillis and P. aeruginosa.
\end{abstract}

Keywords_-Lysine-Salicylaldehyde ;Schiff base; Rare-Earth Complexes; Synthesis; Bioactivity.

\section{Introduction}

Schiff bases and their metal complexes have been widely Used in medicines, industrial catalysis, chemical analysis, metal corrosion and photochromism ${ }^{[1-4]}$, due to their special biological functions. Early in the middle of the twentieth century, Rasenberg have found that amino acid-Schiff bases could inhibit cell division of E. coli. And then, a new field in the drug discovery research has been inaugurated since the antibacterial and anticancer activities of amino acid-Schiff bases were confirmed in $1969^{[5-9]}$.In recent years, with the development of functional complexes and bioinorganic chemistry, transition metal complexes of amino acid-Schiff bases also have made considerable progress. For example, they can be used as anticarcinogen, catalyzer of transamination of vitamin $\mathrm{B}_{6}$, carrier of biotic ligand model, antioxidant, and so on. Therefore, to study the amino acidSchiff base complex is very significant.

In this study, two novel of Rare-Earth (indium

\author{
ZENG Zhi-gang \\ School of Nuclear Technology and Chemistry \& Biology, \\ Hubei University of Science and Technology, \\ Xiangning, 437100,China \\ Liyan750607@163.com
}

and thorium) Complexes with Schiff base from LysineSalicylaldehyde (Lys-Sal) were synthesized via the drop by drop reaction. The title complexes were confirmed by molar conductance, elemental analysis, IR and UV-visible. The bioassay revealed that the title complexes displayed good antibacterial activities. For example, they were effective in controlling S. aureus, E. coli, B. subtillis and P. aeruginosa. And to our knowledge, indium and thorium complexes with Lys-Sal Schiff base have not been reported.

\section{EXPERIMENT}

\section{A. Meterial and Instruent}

All the analytical grade reagents were purchased from commercial sources and used without further purification. Melting points were determined with an uncorrected X-4 digital melting point apparatus. UV spectra were measured on a ZF-6 ultraviolet analyzer at room temperature. IR spectra were recorded by using $\mathrm{KBr}$ pellets on a FTIR-8400S infrared spectrometer. Elemental analyses were determined with VarioEL type III elemental analyzer.

B. Synthesis

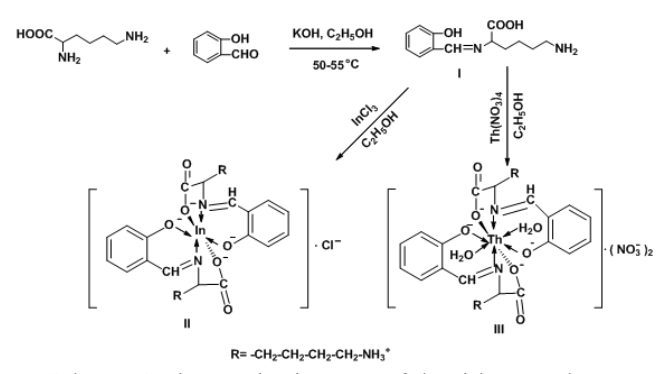

Scheme 1 The synthesis route of the title complexes I, II 


\section{B.1.Synthesis of Lys-Sal Schiff base (I)}

Lysine (1.46 g, $10.0 \mathrm{mmol}), \mathrm{KOH}$ (0.56 g, 10.0mmol)

and anhydrous ethanol $(100 \mathrm{~mL})$ were added into a dry threeneck flask. The mixture was heated to $50{ }^{\circ} \mathrm{C}$ until it was dissolved completely. Then, salicylaldehyde (1.22g, 10.0 mmol) which was dissolved in anhydrous ethanol $(50 \mathrm{~mL})$ was added slowly to the stirring mixture. The reaction was stirred at $55{ }^{\circ} \mathrm{C}$ for $0.5 \mathrm{~h}$ according to TLC analysis. After the $\mathrm{pH}$ adjusted to $6 \sim 8$, the final mixture was filtered off by suction, and then washed with ether. The crude was recrystallized from anhydrous alcohol to yield the Lys-Sal Schiff base (I) as a yellow powder $\left(1.56 \mathrm{~g}\right.$, yield $62.3 \%$, m.p. $\left.228.1 \sim 229.6^{\circ} \mathrm{C}\right)$.

B.2. Synthesis of rare-earth metal complexes with Lys-Sal Schiff base (II)

To a stirred saturated solution of compd (I) $(0.5 \mathrm{~g}, 2.0$ mmol) in anhydrous ethanol, another saturated solution of Indium chloride $(0.22 \mathrm{~g}, 1.0 \mathrm{mmol})$ in anhydrous ethanol was added dropwise. The reaction was stirred at $55{ }^{\circ} \mathrm{C}$ until the finalization (appr $1.5 \mathrm{~h}$ ) according to TLC analysis. Then, the mixture was concentrated in vacuo. Finally, the crude was recrystallized with anhydrous alcohol to obtain the title compd (II) as a yellow powder $\left(0.35 \mathrm{~g}\right.$, yield $54.1 \%$, D.T. $\left.255^{\circ} \mathrm{C}\right)$.

Complex (III) was prepared by the same method as mentioned above and obtained as a yellow powder $(0.59 \mathrm{~g}$, yield $67.2 \%$, D.T. $283^{\circ} \mathrm{C}$ ).

\section{RESUlts AND DISCUSSION}

\section{A. Elemental analysis and molar conductance}

Elemental analysis and molar conductance values were listed in Tab. 1. The complexes were dissolved in DMF solution $\left(1.0 \times 10^{-3} \mathrm{~mol} \cdot \mathrm{L}^{-1}\right)$ and their molar conductances were determined at $25^{\circ} \mathrm{C}$. It was obvious that molar conductivities of the target complexes I and II were greater than 60 . So, it could be speculated that they were electrolyte.
Tab. 1 Elemental analysis and molar conductance of the compounds

\begin{tabular}{|c|c|c|c|c|c|c|}
\hline \multirow{2}{*}{ Compds } & \multirow{2}{*}{ Formula } & \multicolumn{4}{|c|}{ Elemental analysis (calcd.)/ \% } & \multirow{2}{*}{$\begin{array}{c}\Lambda_{\mathrm{M}} \\
\left(\mathrm{S}^{2} \mathrm{c}^{2}\right. \\
\mathrm{mol}^{-} \\
{ }^{1}\end{array}$} \\
\hline & & $\mathrm{C} \%$ & $\mathrm{H} \%$ & $\mathrm{~N} \%$ & $\mathrm{RE} \%$ & \\
\hline I & $\mathrm{C}_{13} \mathrm{H}_{18} \mathrm{~N}_{2} \mathrm{O}_{3}$ & $\begin{array}{c}62.23 \\
(62.40)\end{array}$ & $\begin{array}{c}7.12 \\
(7.20)\end{array}$ & $\begin{array}{c}11.25 \\
(11.20)\end{array}$ & & \\
\hline II & $\mathrm{InC}_{26} \mathrm{H}_{34} \mathrm{~N}_{4} \mathrm{O}_{6} \mathrm{Cl}$ & $\begin{array}{c}48.26 \\
(48.13)\end{array}$ & $\begin{array}{c}5.33 \\
(5.24)\end{array}$ & $\begin{array}{c}8.86 \\
(8.64)\end{array}$ & $\begin{array}{c}17.57 \\
(17.71)\end{array}$ & 62.43 \\
\hline III & $\mathrm{ThC}_{26} \mathrm{H}_{38} \mathrm{~N}_{6} \mathrm{O}_{14}$ & $\begin{array}{c}35.19 \\
(35.04)\end{array}$ & $\begin{array}{c}4.52 \\
(4.26)\end{array}$ & $\begin{array}{c}9.33 \\
(9.43)\end{array}$ & $\begin{array}{c}26.04 \\
(26.10)\end{array}$ & 70.50 \\
\hline
\end{tabular}

\section{B. UV SPECTRA}

Ultraviolet visible spectra of the free ligand (compd I) were given in Fig.2.1. The four absorption peaks of the ligand at ultraviolet region at 215,241, 276, and $400 \mathrm{~nm}$ were assigned to the band of $\mathrm{n}-\pi^{*}$ transitions of benzene ring and $\mathrm{O}$ atom in phenolic hydroxyl ( $\mathrm{E}_{2}$ band), $\pi-\pi^{*}$ transition of imidogen and benzene ring ( $\mathrm{K}$ band), $\pi-\pi^{*}$ transition of benzene ring ( $\mathrm{B}$ band), and of $n-\pi *$ transition of benzene ring and $\mathrm{N}$ atom in imidogen ( $\mathrm{R}$ band), respectively. And that, the weak absorption intensity of $\mathrm{R}$ band revealed that the electronics transition probability was low. Consequently, it was no doubt that Lys-Sal Schiff base (the free ligand, compd I) has been obtained successfully.

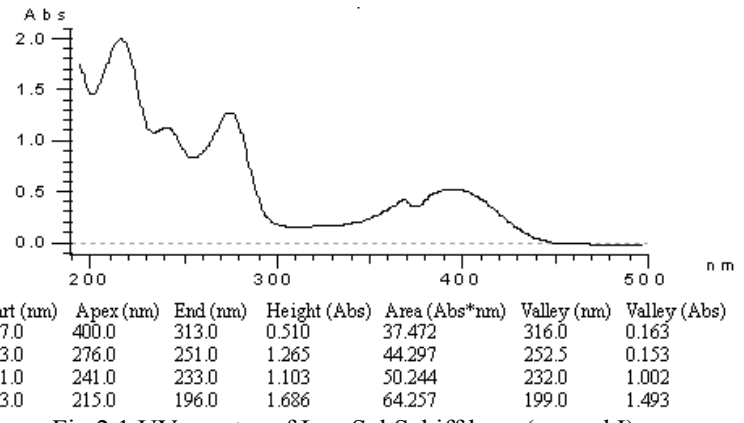

Fig.2.1 UV spectra of Lys-Sal Schiff base (compd I)

Ultraviolet visible spectra of the complexes II and III were shown in Fig.2.2 and Fig.2.3, respectively. At about $400 \mathrm{~nm}$, the original absorption peak disappeared, while a new absorption peak appeared at about $330 \mathrm{~nm}$. The reason could be that the increased electron delocalization has reduced the energy of $\pi-\pi^{*}$ transition due to the coordination between the 
rare-earth metal and the $\mathrm{O}, \mathrm{N}$ atoms in ligand. In other words, the complexes II and III were acquired smoothly.
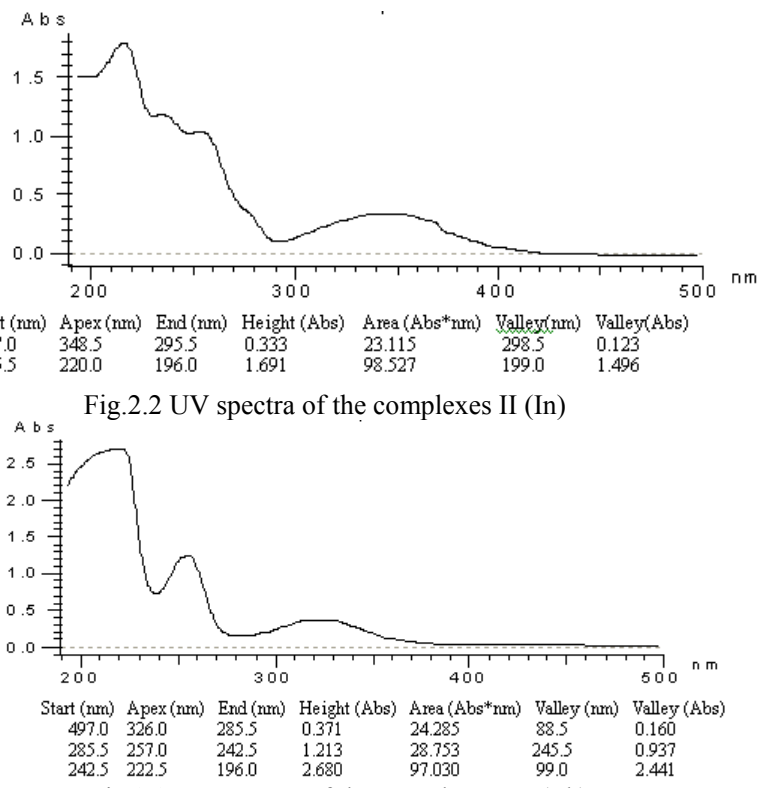

Fig.2.3 UV spectra of the complexes III (Th)

Tab. 2 UV spectra data of Lys - Sal Schiff base and its complexes

\begin{tabular}{ccc}
\hline Compds & $\lambda_{1} / \mathrm{nm}$ & $\lambda_{2} / \mathrm{nm}$ \\
\hline $\mathrm{I} / \mathrm{H}_{2} \mathrm{~L}$ & 276 & 400 \\
$\mathrm{II} / \mathrm{InL}_{2} \mathrm{Cl}$ & 220 & 348 \\
$\mathrm{III} / \mathrm{ThL}_{2}\left(\mathrm{NO}_{3}\right)_{2} 2 \mathrm{H}_{2} \mathrm{O}$ & 257 & 326 \\
\hline
\end{tabular}

\section{Ir Spectra}

A strong absorption bands appeared at a low frequency $1616 \mathrm{~cm}^{-1}$ was attributed to the $\mathrm{C}=\mathrm{N}$ group, which further illustrated the existence of the ligand (compd I). The original absorption peak of phenolic hydroxyl disappeared in the formed complexes. It indicated that the $\mathrm{H}$ atom of phenolic hydroxyl has been eliminated, while the $\mathrm{O}$ anion and metal ion have been cooperated. The absorption bands appeared at $762 \sim$ $745 \mathrm{~cm}^{-1}$ and $656 \sim 601 \mathrm{~cm}^{-1}$ were belonged to the RE-O bond and the RE-N bond, respectively.

In the complex III, an absorption band exhibited at 3413 $\mathrm{cm}^{-1}$ revealed the presence of water, which may be involved in the coordination. And, a strong absorption band appeared at about $1384 \mathrm{~cm}^{-1}$ was ascribed to the free $\mathrm{NO}_{3}{ }^{-}$. It revealed that the $\mathrm{NO}_{3}{ }^{-}$was outside of the complex, which was consistent with the results of molar conductance. Additionally, in the complexes II and III, the $-\mathrm{COO}^{-}$frequency differences between the symmetric and antisymmetric stretching vibration were $94 \mathrm{~cm}^{-1}$ and $111 \mathrm{~cm}^{-1}$, respectively. Therefore, it could be speculated that the carboxyl group of lysine played a role of monodentate in the coordination reaction.

Tab.3 IR spectra data of the Schiff base and its complexes

\begin{tabular}{|c|c|c|c|c|c|c|}
\hline \multirow{3}{*}{ Compds } & \multicolumn{6}{|c|}{$\mathrm{IR}, \sigma / \mathrm{cm}^{-1}$} \\
\hline & \multirow{2}{*}{$\mathrm{v}-\mathrm{OH}$} & \multirow{2}{*}{$v \mathrm{C}=\mathrm{N}$} & \multicolumn{2}{|l|}{$\mathrm{COO}^{-}$} & \multirow{2}{*}{$v R E-O$} & \multirow{2}{*}{$\begin{array}{l}v \mathrm{RE} \\
-\mathrm{N}\end{array}$} \\
\hline & & & vas & va & & \\
\hline $\mathrm{I} / \mathrm{H}_{2} \mathrm{~L}$ & 3435 & 1616 & & & & \\
\hline $\mathrm{II} / \mathrm{InL}_{2} \mathrm{Cl}$ & & 1608 & 1525 & 1431 & 745 & 656 \\
\hline III & & & & & & \\
\hline $\mathrm{ThL}_{2}\left(\mathrm{NO}_{3}\right)_{2}$ & & 1622 & 1584 & 1473 & 762 & 601 \\
\hline $2 \mathrm{H}_{2} \mathrm{O}$ & & & & & & \\
\hline
\end{tabular}

\section{Antibacterial activity}

The bioassay of the free ligand (I) and the title complexes (II, III) was evaluated by filtering paper method against four bacterial species, such as S. aureus, E. coli, B. subtillis and P. aeruginosa. The used level of bactericide was $2 \mathrm{mg} / \mathrm{mL}$. Compd I and II were dissolved in DMSO, while compd III was dissolved in anhydrous ethanol. A similar group was dosed with DMSO and anhydrous ethanol to serve as the control. Obviously, the antibacterial activities of the complexes (II, III) were enhanced in general after chelating (as shown in Tab. 4). It demonstrated that the rare earth metal ions have played a certain promotive role in bioactivity of the complexes.

\begin{tabular}{ccccc} 
Tab. 4 Antibacterial activity of the Schiff base and its complexes \\
\hline Compds & $\begin{array}{c}\text { S. } \\
\text { aureus }\end{array}$ & E. coli & $\begin{array}{c}\text { B. } \\
\text { subtillis }\end{array}$ & $\begin{array}{c}\text { aeruginos } \\
\text { a. }\end{array}$ \\
\hline $\mathrm{I} / \mathrm{H}_{2} \mathrm{~L}$ & - & - & + & - \\
$\mathrm{II} / \mathrm{InL}_{2} \mathrm{Cl}$ & + & + & ++ & + \\
$\begin{array}{c}\mathrm{III} / \mathrm{ThL}_{2}\left(\mathrm{NO}_{3}\right)_{2} 2 \\
\mathrm{H}_{2} \mathrm{O}\end{array}$ & + & + & + & ++ \\
“-"show weak, “+”show strong, “++"show very strong
\end{tabular}




\section{CONCLUSION}

To sum up, two new rare-earth metal complexes with Schiff base of lysine-salicylaldehyde [In(Lys -Sal), Th(Lys Sal)] were synthesized and characterized. And their bioactivities were also evaluated. The bioassay showed that the target complexes have excellent antibacterial activities.

\section{References}

[1] Chen Y H, Ding K Q, Wang Q F, et al. New advances on the application study of Schiff base [J]. Journal of Hebei Normal University, 2003, 27 (1), $71-73$.

[2] Feng X Z, Xia Y H, Liu Z. Synthesis and properties research of the complexes with amino acid Schiff base $[\mathrm{J}]$. Chemical research and application. 2007, 19 (3), 238-243.

[3] Zhao J Q, Han J P, Zhang Y C. Synthesis and catalytic performance for olefin epoxidation of to of the Mn complexes with Alanine salicylaldehyde Schiff base [J]. Catalyst Journal, 2005, 26 (7), 571-576.
[4]Li C Q, Meng X R. Salicylaldehyde the synthesis and characterization of transition metals complexes with salicylaldehyde amine bisSchiff base [J]. Chemical and biological engineering, 2011, 7 (28), 55-57.

[5] Tong L, Yin P Y. Synthesis and characterization of copper and nickel complexes with Schiff base [J]. Journal of South China Normal University (NATURAL SCIENCE EDITION), 2011, 26 (6), 15-18.

[6] Azadbakht, R, Keypour, H. A new Schiff base system bearing two naphthalene groups as fluorescent chemodosimeter for $\mathrm{Zn}^{2+}$ ion and its logic gate behavior [J]. Spectrochimica Acta Part A: Molecular and Biomolecular Spectroscopy, 2012, 85 (1), 293-297.

[7] Beyramabadia, S. A, Morsalia, A. N, N -dipyridoxyl Schiff bases: Synthesis, experimental and theoretical characterization [J]. Spectrochimica Acta Part A: Molecular and Biomolecular Spectroscopy, 2011, 83, 467-471.

[8] Li H L, Li J. Synthesis and Crystal Structure of Charge Transfer Complex (CTC) of 2-Aminobenzothiazole with Its Schiff Base [J]. Chem Crystallogr, 2011, 41, 1844-1949.

[9] Liu G S. Technology of microbiology experiment [M]. Beijing, Science Press, 2007, 135-138. 